\title{
Mario, las aves y el ejército
}

\author{
Santiago Montero Herrero \\ Universidad Complutense de Madrid
}

\begin{abstract}
RESUMEN
ABSTRACT

C. Mario adoptó durante su tercer consulado el águila como emblema de las legiones romanas. Un análisis de las fuentes pone de manifiesto la estrecha vinculación del célebre militar y político con las aves, especialmente a través de la mediación aruspicinal.

Marius adopted during his third consulate the eagle as badge of the roman Legions . An analysis of his sources shows the narrow vinculation between the famous soldier and politic witch the birds, specially through the auruspicined mediation.

\section{PALABRAS CLAVE}

Mario , Aruspicina , Águila , insignias militares.

\section{MAIN WORDS}

Marius, Aruspicinae, Eagle, Military Badge.
\end{abstract}

Un hecho sobradamente conocido en la historia militar romana es la adopción del águila como emblema de las legiones romanas por parte de Cayo Mario durante su tercer consulado ${ }^{1}$. Hasta entonces las legiones romanas tenían cinco símbolos animales: águila, toro, minotauro, caballo y jabalí (aquila, lupi, minotauri, equi, apri: Plin., NHX, 16). En el año 103 a. C. Mario adopta el águila, trasportada por la primera cohorte, como emblema colectivo de la legión y símbolo del mando supremo, diferenciándola de los estandartes de individuales manípulos (signa)².

1 De las numerosas biografías sobre Mario destacaremos: J. Van Ooteghem, Caius Marius, Bruxelles, 1964.

2 Mario deja el águila y abole los demás: Plin., NHX, 16; Paul. 135L; Veget. Epit.3, 6. Para una tipología de las aquilae: cfr. el antiguo estudio de A. von Domaszewski, «Die Fahnen im Römischen Herre», Abhandlungen des archaeologisch-epigraphischen Seminares der Universität Wien, 1885, 1-80 W. 
Dicho pájaro, que primero era de plata y más tarde de oro, aparece con las alas desplegadas sobre un rayo y montado sobre una larga hasta. El aquila era, en origen, una enseña militar persa, adoptada por Alejandro Magno, aunque en Roma su adopción por el ejército se atribuyó siempre a la larga tradición que este ave rapaz gozaba en la religión romana. Las fuentes tardías insisten en ese tipo de razones: «Las águilas, porque fue precisamente esta ave la que proporcionó a Júpiter auspicios favorables en sus combates. En efecto, cuando Júpiter partió para enfrentarse contra los Titanes, según cuentan, se le apareció un águila como presagio, que él interpretó como augurio de victoria y, adoptándola como protectora, diósela como emblema a la legión. Este fue el motivo por el que más tarde se convirtiera en estandarte de los soldados» (Isid., de orig. XVII, 3, 2). Servio señala que el águila como arma de Júpiter contra los Gigantes es una ficción y que el origen del emblema es que le dio buen augurio en la lucha contra el dios Saturno (ad Aen. XI, 561). En cualquier caso para la tropa el aquila legionaria representa un águila real que vuela como signo de buen augurio por delante de las legiones durante su marcha ${ }^{3}$.

La primera aquila de Mario (usada como símbolo por primera vez en la guerra contra los cimbrios: Salust., Catil. 59, 3) tuvo a lo largo del tiempo una carga política (por cuanto estuvo especialmente ligada a los populares) y religiosa muy especial. Catilina tenía guardada la «famosa águila de plata» en su casa donde la hacía objeto de una especial veneración erigiendo en su honor un santuario (aquilam illam argenteam... cui domi tuae sacrarium scelerum tuorum constitutum fuit: Cic., Catil. I, 9, 24). Pocos meses después la misma aquila será exhibida en la batalla de Pistoia (62 a. C.).

Dicha reforma suele considerarse una más dentro de las reformas militares dictadas por $\mathrm{Mario}^{4}$, pero obedece, a mi juicio, a la estrecha vinculación de este político y militar romano con el águila y, en general, con ciertas aves especialmente a través de la mediación aruspicinal.

En efecto, sabemos que los arúspices anunciaron a Mario que alcanzaría por siete veces el consulado pues, siendo niño, cayeron en su regazo siete crías de águila:

\footnotetext{
Seston, «Feldzeichen», en Scripta Varia, Paris, 1980, 263-281. Algunos textos en relación con el águila en otras culturas son interesantes: Jenof., Cyr. 7, 1, 4; Anab. I, 10, 12; Elian., HA XII, 21 (el águila y Gilgamésh); Filostr. Imag. 2, 30 (Evadne). El águila como emblema de las legiones romanas: Veget. 2, 16: praecipuum signum in Romano semper exercitu et totius legionis insigne. Cfr. Caes., Bell. Gall. 4, 25; Tac., Ann. I, 3; Hist. I, 61; Lact. Inst. Div. I, 11.

${ }^{3}$ Cfr. Tac. Ann. II, 17, 2 (para el año 16 d. C.); id., Hist. I, 62; App., BC IV, 101, 425; 128, 532. Para el águila en la vida romana: J.M.C. Toynbee, Animals in Roman Life and Art (Aspects of Greek and Roman Life), London, 1973; N. Himmelmann-Widschütz, «Römische Adler», en Macht und Kultur im Rom der Kaiserzeit, Bonn, 1994, 65-75.

${ }^{4}$ GABBA, E., «Le origini dell'esercito professionale in Roma: I proletari e la riforma di Mario», en Esercito e società nella tarda repubblica romana, Firenze, 1973, 1-45; J. Harmand, «Le prolétariat dans la légion de Marius à la veille du second «Bellum civile», en Problèmes de la guerre à Rome, Paris-La Haye, 1968,61 ss.
} 
«... Por esta razón, a los magistrados, que habían tomado esta decisión después de largo tiempo y con vacilación, les sobrevino un temor demónico, y el recuerdo del séptimo consulado que le había sido profetizado a Mario cuando era un niño; pues dicen que, siendo niño, cayeron en su regazo siete crías de águila y que los adivinos predijeron que alcanzaría por siete veces la magistratura suprema» (Ap., BC I, 61).

«Siendo todavía un niño un día trabajaba en el campo cuando un nido de águila cayó dentro de su manto. Los padres, advertidos, no sabiendo qué pensar, interrogaron a los adivinos y la respuesta fue que aquel muchacho llegaría a ser uno de los hombres más insignes y obtendría el más alto cargo civil y militar, el consulado, en siete ocasiones» (Plut., Mar. 36, 8).

Se trata de «ostentum privatum» puesto en circulación en los últimos años de la vida de Mario. Plutarco añade algo de interés para conocer la difusión de este tipo de presagios. Señala que «algunos» aseguraron que tal hecho sucedió verdaderamente a Mario mientras "otros» que lo escuchó de él alguien que estaba entonces a su lado. El polígrafo griego cree, en cualquier caso, que se trata de una fábula puesto que es sobradamente conocido que el águila no tiene más de dos crías (id., 36). Dicho responsum aruspicinal tiene algunos puntos comunes con la doctrina del arúspice Umbricius Melior sobre los buitres y el número de huevos ${ }^{5}$. Recordemos que su conocimiento de la Etrusca Disciplina le valió una brillante carrera en Roma al servicio de los emperadores de la dinastía Flavia. Al margen de su colaboración con el poder político, Umbricius Melior trató de mantener al día la ciencia adivinatoria etrusca escribiendo una obra, De Etrusca Disciplina, que Plinio cita entre sus fuentes de los libros X y XI. El naturalista latino extrae de ella una teoría sobre el número de huevos puesto por la hembra del buitre:

«Umbricio, el más experto de los arúspices de nuestro tiempo, escribe que [los buitres] ponen trece huevos, que con uno de ellos purifican los otros y el nido, y luego lo tiran.»

Umbricius, haruspicum in nostro aevo peritissimus [vultures] parere tradit ova tredecim, uno ex his reliqua ova nidumque lustrare, mox abdicere (Plin., NHX, 19).

La doctrina de Umbricio carece, por supuesto, de toda base científica puesto que, desde la Historia de los animales (VI, 5 y IX, 2) de Aristóteles se sabía que el buitre ponía sólo dos huevos. Los arúspices contaban con libros de ilustraciones para la identificación de las diferentes especies de aves: sunt praeterea complura genera [avium] depicta in etrusca Disciplina (Plin., NHX, 37). Depicta se referiría no a simples descripciones sino a verdaderos dibujos. Según $\mathrm{C}$. O. Thulin en los ostentaria etruscos cada pájaro en cuestión era representado junto a un texto, una hipótesis recientemente apoyada por J. Linderski6.

5 Sobre Umbricius, cfr. D. Briquel, «Sur un fragment d’Umbricius Melior. L' interprétation par un haruspice de la légende de fondation de Rome?», Caesarodunum suppl. n. ${ }^{\circ} 64,1995,22-23$. Como fuente de Plinio: F. Capponi, Le fonti del X libro della Naturalis historia di Plinio, Genova, 1985.

6 Thulin, C.O., Die Etruskische Disciplin, Darmsadt, 1968, III, 107, opinión compartida por J. Linderski, «The Augural Law», en ANRW II, 16.3 (Berlin-New York, 1986), 2248 n. 400. 
Es probable que los libros de la Etrusca disciplina estableciesen, además, una correspondencia entre la aparición de ciertas aves y la duración del tiempo. El águila tenía el valor de año, mientras el buitre el de siglo. Las siete águilas anunciando los siete consulados Mario o los doce buitres anuncio de los doce siglos de Roma sirven respectivamente de ejemplos.

A partir del año 100, cuando Mario alcanzaba el consulado por sexta vez, comenzó a distanciarse tanto de Saturnino como de la causa popular. Su obligación como cónsul de acabar con los desórdenes callejeros y defender la supervivencia de las instituciones así como el decidido apoyo prestado no sólo por la oligarquía senatorial y los caballeros sino también por buena parte de la plebe urbana, explica su enfrentamiento con los populares. Para recuperar la popularidad perdida, Mario decidió retirarse temporalmente de la vida política viajando al Oriente a finales del año 99. Fue durante aquel periodo cuando vió un águila llevando una serpiente entre sus garras que la había herido, arrojándola al agua antes de volar hacia oriente. Dicha aparición fue interpretada como anuncio de su revancha sobre Sila y su entrada en Roma.

Aquel hecho, considerado como un omen, fue muy celebrado. Cicerón centró en él su poema, Marius: el águila, «la dorada mensajera de Jove, de admirable figura» tras estrangular con sus garras a una serpiente que le había atacado, saliendo de una encina, remontó el vuelo hacia el oriente» (Quare glandifera illa quercus, ex qua olium evolavit nuntia fulva lovis, miranda visa figura, nunc sit haec: De legibus I, 2). El fragmento más largo de aquella composición poética ${ }^{7}$ se conserva en el De divinatione:

«Entonces, de pronto, la alada compañera de Júpiter altisonante, lastimada por la mordedura de una serpiente, se yergue sobre el tronco del árbol y atraviesa con fieras garras a la culebra, que, casi exánime, cimbrea poderosamente su cuello multicolor, desgarrándola, mientras se retuerce, y haciendo brotar la sangre con su pico; ya saciado su espíritu y habiendo ya vengado el duro dolor, arroja a la exhalante culebra, deja caer sus trozos sobre el agua, y torna, desde donde el sol se pone, hasta el brillante orto. Cuando a ésta, que con raudas alas se delizaba volando, divisó Mario, augur del divino numen, y hubo advertido esto los faustos signos de su ensalzamiento y regreso, el propio padre del cielo resonó por el lado izquierdo.

Así es como Júpiter refrendó el ilustre presagio del águila» (de div. I, 106)

Cicerón, conociendo el episodio de Mario, pero sin duda influido también por Homero (II. XII, 200ss.), alude en el pasaje al regreso de Mario del exilio anuncia-

7 Marius es citado sólo cinco veces en la literatura latina, tres de ellas en obras del propio Cicerón: de div. I, 106; de leg., 1; ad Att. 12, 49, 1 y por tanto el poema debió ser escrito antes del año 52, quizá en los primeros meses del 59. Cicerón, de div. I, 106 emplea el término praepetibus para referirse al águila que se le apareció a Mario, el mismo que Livio I, 34, 9 cuando narra el episodio del águila que descendió sobre Tarquinio Prisco. 
do por un águila. Que el águila se dirija hacia el oriente parece ser signo de buen augurio o anuncio de un "cambio de suerte». Mario, a quien Cicerón admiraba, era augur in absentia desde el 97 (dos años después, por cierto, de su retiro temporal al Oriente) pero también era interpretandarum religionum peritissimus (Val. Max. I $5,5)$. De hecho, el signo dado por el ave guarda poca relación con la vieja auspicatio romana y prueba de ello es que, en el último verso, se nos dice que el sonido del trueno desde el lado izquierdo del cielo confirmó el ilustre aquilae... omen. H.W. Benario señaló hace años en un artículo ${ }^{8}$ que el propósito de esta composición no era sólo elogiar al gran general y político romano sino sobre todo glorificar a un miembro de la familia de César en una época - años 60-59- en la que éste daba pruebas inequívocas de su futuro poder.

Los arúspices intervenían frecuentemente en la interpretación de prodigios protagonizado por pájaros, como el que tuvo lugar en el año 88 a. C., en vísperas de la guerra entre Mario y Sila. Mientras el Senado discutía con «los más sabios de los adivinos etruscos» en el interior del templo de Bellona sobre los prodigios acaecidos en días anteriores, un pájaro -quizá un gorrión (strouthòs) - entró volando en su interior con una cigarra en el pico: tras dejar caer un trozo del insecto en el templo, salió volando con el otro en el pico (Plut., Syll. 7, 12-13). Los «intérpretes de los prodigios» (teratoskópoi), es decir, los arúspices, dedujeron del prodigio que se produciría una sedición y disensiones entre los propietarios de tierras y la plebe urbana y del Foro, pues esta última es ruidosa como la cigarra y los campesinos viven en el campo como pájaros.

No cabe duda de que Mario mantuvo desde muy pronto buenas relaciones con los arúspices. Obsecuente señala que en el año 108 a. C., es decir, durante los consulados de Sergio Galba y Marco Escauro, fueron vistos en la ciudad de Roma un ave incendiaria y un búho (Avis incendiaria et bubo in urbe visae: Obs. 40) pero Plinio señala, deteniéndose en aquel prodigio, que tuvo lugar un año después, es decir, bajo el consulado de Casio y Mario:

«De mal augurio es también el ave llamada incendiaria a causa de la cual Roma, según encontramos en los Anales, tuvo que ser purificada muchas veces, como en el consulado de Lucio Casio y Cayo Mario [107 a. C.], año en el que se celebró la misma ceremonia también por la aparición de un búho. Qué clase de ave es ésta ni se ha descubierto ni se nos ha transmitido. Algunos lo explican así: es incendiaria qualquiera a la que se ha visto con carbón tomado de las aras o de los altares; otros la llaman spinturnix pero no he encontrado quién fuese capaz de indicar con precisión esta especie»

Inauspicata est et incendiaria avis, quam propter saepenumero lustratam urbem in annalibus, sicut L. Cassio C. Mario cos., quo anno et bubone viso lustratam esse. Quae sit avis ea, non reperitur nec traditur. Quidam ita interpretantur, incendiariam esse quaecumque apparuerit carbonem ferens ex aris vel altaribus; alii spinturnicem vocant, sed haec ipsa quae esset inter aves, qui se scire diceret non inveni $(\mathrm{NH} \mathrm{X}, 36)$

8 Benario, H.W., «Cicero's Marius and Caesar», Classical Philology 52, 3, 1957, 177-181. 
Este «pájaro de fuego» ha sido identificado por F. Capponi ${ }^{9}$ con el Pyrrhocorax graculus, amante del fuego en los meses invernales. Pero la hipótesis de que se trate de cuervos que cogen carbón de los altares sacrificiales provocando un incendio es bastante convincente. Si los cuervos, como parece deducirse del pasaje pliniano, fueron consideradas por ello «aves incendiarias» —fijémonos que Plinio emplea la expresión quaecumque (avis)— se trataba de un gravísimo prodigio. El carácter prodigial viene confirmado por la celebración en 107, tras la aparición de aves incendiarias, de una lustración en la ciudad. Su aparición, como la del búho, venía siendo registrada también en las tablas de prodigios y fue sin duda alguna expiada por los arúspices.

De los prodigios registrados en el año 104, durante el consulado de Mario y C. Flavio Fimbria las aves protagonizaron dos: un búho fue visto en las afueras de Roma y unos buitres murieron sobre una torre alcanzados por un rayo (Bubo extra urbem visus.... Fulminis ictu vultures super turrem exanimati: Obs., 43). Se trata de dos prodigios públicos que sin duda se referían a la ciudad de Roma pero que debieron ser convenientemente expiados. Sabemos que en el año 102, durante el cuarto consulado de Mario, el templo de Júpiter fue alcanzado por un rayo cuando estaba cerrado. Dice Obsecuente que el arúspice Emilio Potense, recibió una recompensa - a mi juicio probablemente de manos del propio Mario — «por haber sido el primero en manifestar cómo debía ser la expiación de este prodigio mientras los demás lo ocultaban porque se presagiaba la ruina para ellos y para sus hijos» (Obs. 44).

Cuando Mario, en el 87 recuperó el poder aprovechando la ausencia de Sila se desencadenaron matanzas, saqueos y en general persecuciones de los miembros mas destacados del partido contrario. Mario y Cinna dieron su palabra al cónsul Octavio de que nada le sucedería y Apiano añade: «los augures y adivinos habían predicho que él no sufriría daño alguno, pero sus amigos le aconsejaron que huyera» $(B C I, 71)$ lo que pone de manifiesto no sólo la sintonía de los arúspices con Mario sino su intervención en la política así como su considerable poder.

Pero fijémonos en algo que reaparecerá más tarde en otros imperatores del último siglo de la República: con Mario aparecen omina o presagios que se refieren individualmente a él y que —a diferencia de los prodigios del 104 y 102 a. C.- tienen lugar al margen del ámbito público (Plut., Mar. 36, 8-11). Durante su campaña contra el rey númida Jugurta, un arúspice, al que Mario consultaba con frecuencia, le anunció un porvenir brillante como ponen de manifiesto varias fuentes:

«Por el mismo tiempo, a C. Mario, que por caso ofrecía en Útica un sacrificio a los dioses, le dijo el arúspice que había señales de grandes y portentosos sucesos (magna atque mirabilia portendi haruspex dixerat): por lo tanto, que pusiese por obra, confiando en los dioses, lo que meditaba, y probase suerte sin descanso una vez y otra, pues todo le sucedería prósperamente» (Salust., Jug., 63, 1)

9 CApponi, F., «Avifauna nella divinazione en el mito», Latomus 36, 1977, 451. 
«El hígado se encuentra a la derecha: aquí se encuentra el llamado caput extorum...Faltaba también con ocasión del sacrificio de Cayo Mario en Útica» (defuit et C. Mario, cum immolaret Uticae) (Plin., NH XI, 189)

«Mario anduvo el largo camino que había del campamento a Útica sobre el mar en dos días y una noche y antes de embarcarse hizo un sacrificio. Dícese haberle anunciado el adivino que los dioses le pronostiocaban hechos y sucesos muy superiores a toda esperanza, con lo que partió sumamente confiado». (Plut., Mar., 8, 8).

Por primera vez, dice M.-L. Haak, de todas las consultas efectuadas en el ámbito militar, la interpretación del arúspice no se aplica al resultado del combate o de la guerra «mais vise la carrière même de ce consultant» ${ }^{10}$. La respuesta aruspicinal no va referida al destino del ejército, en su colectividad, sino únicamente al futuro del jefe. La consulta constituía, dice Haak, uno de los instrumentos de propaganda personal de los jefes ambiciosos. El ejemplo de Mario parece haber sido un precedente no sólo para Sila sino decenios más tarde también para Octavio ${ }^{11}$. El prodigio público ha dado paso al omen privado que consagra el carisma del jefe y exalta la fortuna personal de los grandes generales de finales de la República y, después, de los emperadores y por ello casi todos los omina imperii (desde Mario a Tiberio) sobrevienen cuando éstos eran privati.

La influencia de los arúspices del entorno de Mario debió dejarse sentir en la identificación de las aves con el prodigio y su interpretación. Sabemos que el ejército de Mario, quizá siguiendo la recomendación de estos adivinos, buscaba la proximidad de una pareja de águilas cuando se escogía el emplazamiento sobre el que levantar el campamento (Ex eo notatum, non fere legionis umquam hiberna esse castra ubi aquilarum non sit iugum: Plin., NHX 16).

Algo parecido sucedía con los buitres. Los soldados sabían que los buitres tenían un sentido especial para conocer el desenlace de la batalla y su vuelo era atentamente seguido por la tropa como anuncio de lo que pronto sucedería. La tradición etrusca también se interesó por esas dotes proféticas del buitre: el arúspice Umbricio sostenía que «con tres días de antelación [los buitres] vuelan hacia los lugares donde va a haber cadáveres» (triduo autem ante advolare eos, ubi cadavera futura sunt: Plin., $N H \mathrm{X}, 19)$ pero si se presentaban durante la marcha, el vuelo era interpretado como buen presagio. Se entiende así lo que Plutarco narra referido al ejército de Mario'12:

10 HAACK, M.-L., Les haruspices dans le monde romain, Bordeaux, 2003, 52. E. Rawson, «Religion and Politics in the Late Second Century B.C. at Rome», Phoenix 28, 1974, 206, refiriéndose a los omina y prodigia que están presentes en su biografía, escribe: «his lack, earlier, of any official religious office may have been one reason for his irregular activity in the area». Cfr. T.F. Carney, «The Picture of Marius in Valerius Maximus», RhM 105, 1962, 303ss.

11 HAACK, M.-L (op.cit. n. 10), 53. Compárese los omina de Mario con los de Augusto: M. B. Flory, «Octavian and the omen of the Gallina Alba», CJ 84, 1989, 343-356. S. Montero, «Livia y la adivinación inductiva», Polis 6, 1994, 225-267.

12 HeuRgon, J., «Voltur», REL 14, 1936, 109-118. Sobre las propiedades proféticas del buitre, cfr. el citado pasaje de Umbricius (NHX,19). 
«En cuanto al maravilloso prodigio de los buitres lo refiere Alejandro de Mindos, y es que antes de una batalla en la que después obtendría la victoria, sobre los ejércitos de Mario aparecían siempre dos buitres que los acompañaban y eran reconocibles por un collar de bronce puestos por los soldados cuando los habían capturado, antes de dejarlos volar. Desde entonces los soldados los reconocían y los saludaban y se alegraban de verlos aparecer al comienzo de una marcha, siendo casi un buen auspicio de lo que habría de suceder» (Plut., Mar. 17). 